\title{
Reduction of boron thermal diffusion in silicon by high energy fluorine implantation
}

\author{
H. A. W. El Mubarek and P. Ashburn ${ }^{\text {a) }}$ \\ Department of Electronics \& Computer Science, University of Southampton, Southampton SO17 1BJ, United \\ Kingdom
}

(Received 8 July 2003; accepted 27 August 2003)

\begin{abstract}
This letter investigates the effect of a deep $\mathrm{F}^{+}$implant on the diffusion of boron in silicon. The effects on boron thermal diffusion and transient enhanced diffusion are separately studied by characterizing the diffusion of a buried boron marker layer in wafers with and without a $185 \mathrm{keV}$, $2.3 \times 10^{15} \mathrm{~cm}^{-2} \mathrm{~F}^{+}$implant, and with and without a $288 \mathrm{keV}, 6 \times 10^{13} \mathrm{~cm}^{-2} \mathrm{P}^{+}$implant. In samples given both $\mathrm{P}^{+}$and $\mathrm{F}^{+}$implants, the fluorine completely eliminates the transient, enhanced boron diffusion caused by the $\mathrm{P}^{+}$implant, and in samples implanted with $\mathrm{F}^{+}$only, the fluorine suppresses the boron thermal diffusion by $65 \%$. These results are explained by the effect of the fluorine on the vacancy concentration in the vicinity of the boron profile. (C) 2003 American Institute of Physics. [DOI: 10.1063/1.1622434]
\end{abstract}

The minimization of boron diffusion is vitally important in metal-oxide-semiconductor (MOS) transistors for the control of short channel effects, ${ }^{1}$ and in bipolar transistors for achieving narrow base widths and hence high values of cutoff frequency. ${ }^{2,3}$ However, this is difficult to achieve in practice because of both boron thermal diffusion and transient, enhanced diffusion due to damage created during ion implantation. ${ }^{4}$

Recently, there has been considerable interest in the use of fluorine to suppress transient enhanced boron diffusion (TEBD) in silicon. ${ }^{5-11}$ Early work showed that reduced TEBD was obtained when $\mathrm{BF}_{2}^{+}$was implanted instead of $\mathrm{B}^{+} .^{5}$ In a later work, Ohyu et al. ${ }^{6}$ implanted $\mathrm{F}^{+}$separately and showed that the fluorine implant reduced TEBD and increased the boron activity. However, there have also been contradictory reports in the literature, which showed that fluorine implants had little or no effect on boron diffusion ${ }^{12}$ and even enhanced boron diffusion in amorphous silicon. ${ }^{13}$

While there has been considerable research on the effect of fluorine on TEBD, little has been published on the effects of fluorine on the thermal diffusion of boron. In this letter, a study is made of the effect of fluorine on the diffusion of boron in buried marker layers. Samples with and without a $\mathrm{P}^{+}$implant are studied so that the effect of fluorine on both TEBD and thermal diffusion can be separately characterized. It is shown that fluorine not only eliminates TEBD, but also dramatically reduces boron thermal diffusion.

Molecular-beam epitaxy (MBE) at $520{ }^{\circ} \mathrm{C}$ was used to grow buried boron-doped marker layers on (100) silicon wafers. Samples of the same epitaxial layer were separated into four different groups, the first having no implants (unimplanted), the second having a phosphorus implant only $\left(\mathrm{P}^{+}\right.$ implanted), the third a phosphorus and a fluorine implant $\left(\mathrm{P}^{+}\right.$and $\mathrm{F}^{+}$implanted), and the fourth a fluorine implant only ( $\mathrm{F}^{+}$implanted). A $288 \mathrm{keV}, 6 \times 10^{13} \mathrm{~cm}^{-2}$ phosphorus implant was used and was chosen to be similar to those used for a selective implanted collector in a bipolar process. ${ }^{14} \mathrm{~A}$

${ }^{a)}$ Electronic mail: pa@ecs.soton.ac.uk
$185 \mathrm{keV}, 2.3 \times 10^{15} \mathrm{~cm}^{-2} \mathrm{~F}^{+}$implant was used and the energy was selected such that the fluorine range was the same as that of the phosphorus implant. The layers were annealed by rapid thermal annealing in nitrogen at $1000{ }^{\circ} \mathrm{C}$ for $30 \mathrm{~s}$. Boron (B11) and fluorine (F19) concentration depth profiles were obtained on all samples by secondary ion mass spectroscopy (SIMS) using a $5 \mathrm{keV}$ oxygen beam with oxygen flooding.

Figure 1(a) shows the effect of a $\mathrm{P}^{+}$implant on the boron diffusion in the absence of a $\mathrm{F}^{+}$implant. It can be seen that the $\mathrm{P}^{+}$implant causes significant extra diffusion of the boron marker layer compared with the unimplanted control sample. Comparing the boron profiles at a concentration of $1 \times 10^{17} \mathrm{~cm}^{-3}$, we find that the width of the $\mathrm{P}^{+}$implanted boron profile is $138 \mathrm{~nm}$, compared with $108 \mathrm{~nm}$ for the unimplanted boron profile and $48 \mathrm{~nm}$ for the as-grown boron profile. These results indicate that the phosphorus implant gives rise to TEBD. We also notice that the boron profile in the $\mathrm{P}^{+}$implanted sample is asymmetrical, with more diffusion into the substrate. This is due to the backflow of excess interstitials, as has been reported previously for TEBD caused by a silicon implant. ${ }^{4}$

Figure 1(b) shows the effect of a $\mathrm{F}^{+}$implant on TEBD in samples implanted with $\mathrm{P}^{+}$. It is clear that there is dramatically less boron diffusion in the sample implanted with $\mathrm{F}^{+}$. Comparing the boron profiles at a concentration of $1 \times 10^{17} \mathrm{~cm}^{-3}$, we observe that the diffusion of boron into the substrate in the $\mathrm{P}^{+}$and $\mathrm{F}^{+}$implanted sample $(14 \mathrm{~nm})$ is $42 \mathrm{~nm}$ less than that in the $\mathrm{P}^{+}$implanted sample $(56 \mathrm{~nm})$, which indicates that the $\mathrm{F}^{+}$implant has reduced the boron diffusion by $75 \%$. Comparing Figs. 1(a) and 1(b), we notice that the boron diffusion for the $\mathrm{P}^{+}$and $\mathrm{F}^{+}$implanted sample is less than that for the unimplanted sample in Fig. 1(a). This indicates that the $\mathrm{F}^{+}$implant has not only totally suppressed the boron transient enhanced diffusion caused by the $\mathrm{P}^{+}$implant, but has also greatly reduced the thermal diffusion.

Figure 1(c) shows the effect of a $\mathrm{F}^{+}$implant on boron thermal diffusion in samples not given a $\mathrm{P}^{+}$implant. It can be seen that there is considerably less diffusion in the 


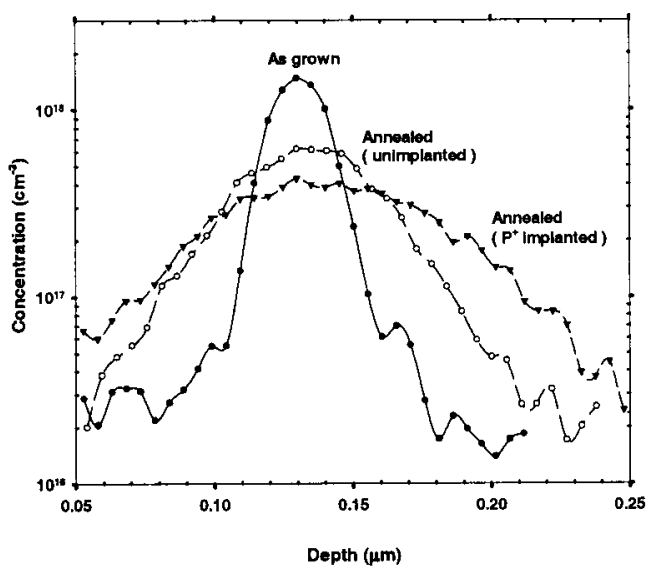

(a)

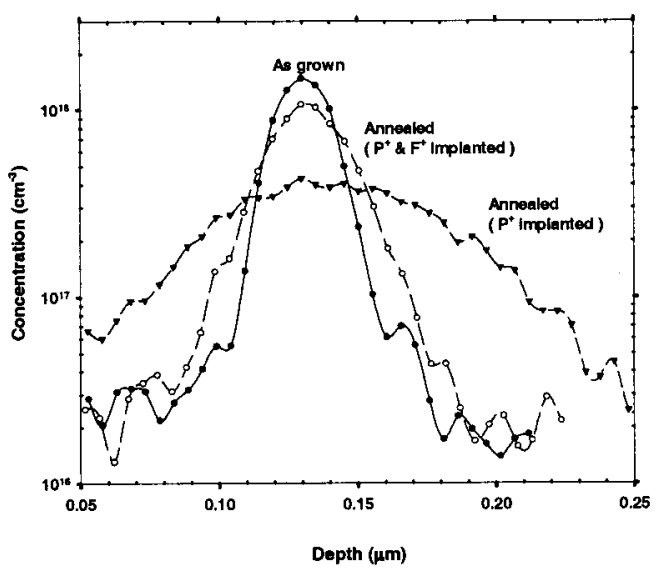

(b)

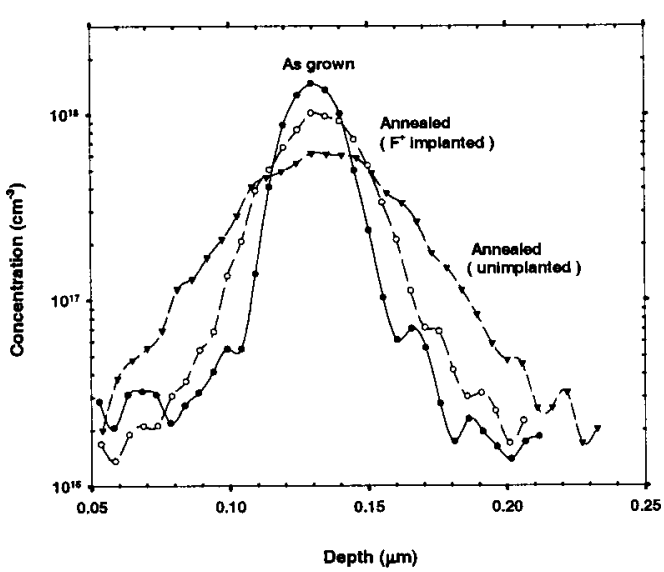

(c)

FIG. 1. Boron SIMS profiles of a buried boron marker layer after MBE growth and anneal for $30 \mathrm{~s}$ at $1000^{\circ} \mathrm{C}$. (a) An unimplanted sample and a sample implanted with $\mathrm{P}^{+}$prior to anneal; (b) samples implanted with $\mathrm{P}^{+}$ only and with both $\mathrm{P}^{+}$and $\mathrm{F}^{+}$prior to anneal; (c) an unimplanted sample and a sample implanted with $\mathrm{F}^{+}$only prior to anneal.

sample implanted with $\mathrm{F}^{+}$than in the unimplanted sample. Comparing the boron profiles at a concentration of $1 \times 10^{17} \mathrm{~cm}^{-3}$, we find that the diffusion of boron into the substrate for the $\mathrm{F}^{+}$implanted sample $(11 \mathrm{~nm})$ is $20 \mathrm{~nm}$ less than that in the unimplanted sample $(31 \mathrm{~nm})$, which indicates that the $\mathrm{F}^{+}$implant has reduced the thermal boron diffusion by $65 \%$.

Figure 2 compares the as-implanted fluorine profile with Downloaded 23 bec 2003 to 152.78.67.91. Redistribution subject

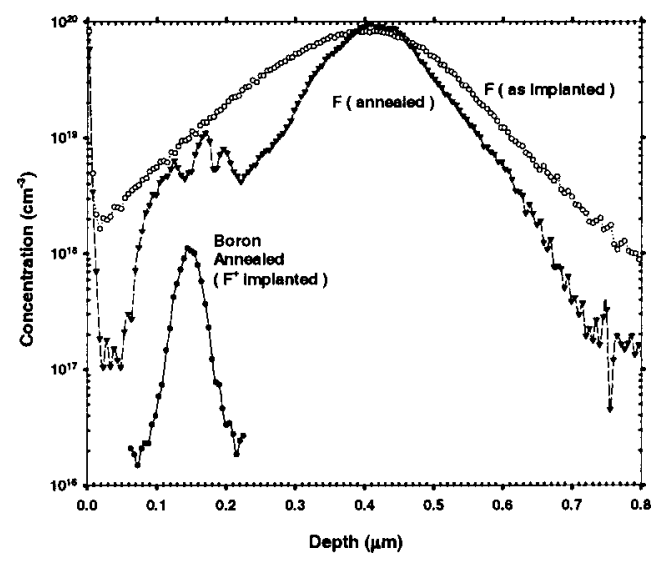

FIG. 2. Comparison of fluorine profiles after implant and after anneal for 30 $\mathrm{s}$ at $1000^{\circ} \mathrm{C}$. A boron profile after $\mathrm{F}^{+}$implant and anneal is also shown for comparison.

the annealed fluorine and boron profiles of the $\mathrm{F}^{+}$implanted sample discussed in Fig. 1(c). The annealed fluorine profile is considerably different than the as-implanted profile and shows two broad peaks. The deeper peak lies at a depth of $0.43 \mu \mathrm{m}$, with a peak concentration of $9.11 \times 10^{19} \mathrm{~cm}^{-3}$. This peak concentration is slightly higher than the asimplanted peak concentration of $8.32 \times 10^{19} \mathrm{~cm}^{-3}$, and slightly deeper than the as-implanted range of $0.42 \mu \mathrm{m}$. The shallower peak lies between 0.05 and $0.22 \mu \mathrm{m}$ and shows three small peaks at depths of $0.13,0.17$, and $0.20 \mu \mathrm{m}$. The integrated dose of the as-implanted fluorine SIMS profile is $2.3 \times 10^{15} \mathrm{~cm}^{-2}$. The integrated fluorine dose after anneal is $1.6 \times 10^{15} \mathrm{~cm}^{-2}$, indicating that $30 \%$ of the implanted fluorine has been lost during the anneal. The majority of the fluorine lost comes from the surface side of the fluorine peak, but there is also some loss of fluorine from the substrate side. The fluorine profile after anneal in the sample implanted with both $\mathrm{P}^{+}$and $\mathrm{F}^{+}$is not shown but was broadly similar to that shown in Fig. 2.

The results in Figs. 1(b) and 1(c) show that the high energy $\mathrm{F}^{+}$implant has not only completely eliminated TEBD, but has also given a substantial $65 \%$ reduction in the thermal diffusion of boron. Reductions in the transient enhanced diffusion of boron by fluorine have been reported previously in the literature, ${ }^{5-11}$ and our results are comparable with the largest suppressions reported. ${ }^{10}$ Suppression of boron thermal diffusion has not been reported previously, and possible explanations are discussed subsequently.

Boron thermal diffusion is mediated by interstitials, and hence our results suggest that the fluorine implant is suppressing the interstitial concentration in the vicinity of the boron profile. Simulations of vacancy and interstitial profiles following a $\mathrm{P}^{+}$implant, ${ }^{15}$ have predicted a shallow, vacancyrich region extending from the surface to a depth of about $R_{p} / 2\left(R_{p}=\right.$ implantation range) and a deeper, interstitial-rich region beginning at a depth just beyond $R_{p}$. The correlation between these simulations and the fluorine peaks in Fig. 2 are very strong, suggesting that the deep F peak may be due to fluorine trapped at interstitial-type defects and the shallow F peak due to fluorine trapped at vacancy-type defects. There is considerable evidence in the literature for the formation of vacancy-fluorine clusters ${ }^{16}$ and complexes, ${ }^{11,17}$ and for the formation of fluorine-interstitial clusters close to the implanAIP license or copyright, see http://ojps.aip.org/aplo/aplcr.jsp 
tation range. ${ }^{18}$ The trapping of fluorine at interstitial type defects at the deep fluorine peak would prevent the backflow of excess interstitials and hence eliminate TEBD. The presence of fluorine-vacancy complexes in the vicinity of the boron profile would explain both the presence of the shallow fluorine peak and the suppression of the boron thermal diffusion due to the presence of a local excess vacancy concentration resulting in an undersaturation of the interstitial concentration. Another possibility is a chemical interaction between the boron and the fluorine, which would explain the presence of the shallow fluorine peak. If this chemical interaction prevented the interaction of boron with interstitials ${ }^{9,10}$ or reduced the mobility of interstitial boron, ${ }^{19}$ it could also explain the suppression of boron thermal diffusion. Ab initio calculations have suggested the existence of a stable B-F cluster in which the fluorine intrudes into the $\mathrm{B}-\mathrm{Si}$ bond and pushes the subsitutional boron away from its initial position. ${ }^{11}$ However, ab initio calculations have also been reported to show no significant binding energies between boron and fluorine. ${ }^{16}$ These considerations suggest that the most likely explanation for the suppression of boron thermal diffusion by fluorine is an excess vacancy concentration in the vicinity of the boron profile due to the formation of vacancy-fluorine clusters and hence an undersaturation in the interstitial concentration. However, a chemical interaction between boron and fluorine cannot be completely discounted at the present time without further experimental work.

In conclusion, a study has been made of the effect of a high energy $\mathrm{F}^{+}$implant on the thermal diffusion of boron from a shallow marker layer grown by MBE and annealed for $30 \mathrm{~s}$ at $1000^{\circ} \mathrm{C}$. In samples implanted with $\mathrm{F}^{+}$only, the fluorine reduces the boron thermal diffusion in comparison to annealed unimplanted samples by $65 \%$, and in samples implanted with $\mathrm{P}^{+}$and $\mathrm{F}^{+}$, the fluorine completely suppresses transient enhanced boron diffusion. Fluorine SIMS profiles show a broad fluorine peak in the vicinity of the boron profile, and a deeper peak just beyond the range of the fluorine implant. An explanation for the boron thermal diffusion suppression is proposed in which the fluorine increases the excess vacancy concentration in the vicinity of the boron profile due to the formation of fluorine-vacancy clusters, and hence creates an undersaturation in the interstitial concentration.

The authors acknowledge Rob Price and Jing Zhang for providing the MBE wafers, and the Surrey University Ion Implantation Center for providing the implants. EPSRC is acknowledged for funding the work.

${ }^{1}$ P. Ranade, H. Takeuchi, W.-C. Lee, V. Subramanian, and T.-J. King, IEEE Trans. Electron Devices 49, 1436 (2002).

${ }^{2}$ P. Ashburn, Design and Realization of Bipolar Transistors (Wiley, New York, 1988).

${ }^{3}$ Md. R. Hashim, R. F. Lever, and P. Ashburn, Solid-State Electron. 43, 131 (1999).

${ }^{4}$ D. J. Eaglesham, P. A. Stolk, H.-J. Gossmann, and J. M. Poate, Appl. Phys. Lett. 65, 2305 (1994).

${ }^{5}$ R. G. Wilson, J. Appl. Phys. 54, 6879 (1983).

${ }^{6}$ K. Ohyu, T. Itoga, and N. Natsuaki, Jpn. J. Appl. Phys. 29, 457 (1990).

${ }^{7}$ D. Fan, J. M. Parks, and R. J. Jaccodine, Appl. Phys. Lett. 59, 1212 (1991).

${ }^{8}$ L. Y. Krasnobaev and V. V. Makarov, J. Appl. Phys. 74, 6020 (1993).

${ }^{9}$ J. Liu, D. F. Downey, K. S. Jones, and E. Ishida, Proceedings of the International Conference on Ion Implantation Technology, Kyoto, Japan, 22-26 June 1998 (IEEE, Piscataway, NJ, 1999), Vol. 2, p. 951.

${ }^{10}$ L. S. Robertson, P. N. Warnes, K. S. Jones, S. K. Earles, M. E. Law, D. F. Downey, S. Falk, and J. Liu, Mater. Res. Soc. Symp. Proc. 610, B4.2.1 (2000).

${ }^{11}$ T. S. Shano, R. Kim, T. Hirose, Y. Furuta, H. Tsuji, M. Furuhashi, and K. Taniguchi, Tech. Dig. - Int. Electron Devices Meet., 37.4.1 (2001).

${ }^{12}$ E. Ishida, D. F. Downey, K. S. Jones, and J. Liu, Proceedings of the International Conference on Ion Implantation Technology, Kyoto, Japan, 22-26 June 1998 (IEEE, Piscataway, NJ, 1999), Vol. 2, p. 909.

${ }^{13}$ J. M. Jacques, L. S. Robertson, and K. S. Jones, Mater. Res. Soc. Symp. Proc. 717, C461 (2002).

${ }^{14}$ B. Martinet, H. Baudry, O. Kermarree, Y. Campidelli, M. Laurens, M. Marty, T. Schwartzmann, A. Monroy, D. Bensahel, and A. Chantre, Proceedings of the 31st European Solid-State Device Research Conference, Nuremberg, Germany, 11-13 Sept. 2001 (Frontier Group), p. 97.

${ }^{15}$ M. D. Giles, J. Electrochem. Soc. 138, 1160 (1991).

${ }^{16}$ M. Diebel, S. Chakravarthi, S. T. Dunham, C. F. Machala, S. Ekbote, and A. Jain, Mater. Res. Soc. Symp. Proc. 765, D6.15 (2003).

${ }^{17}$ X. D. Pi, C. P. Burrows, and P. G. Coleman, Phys. Rev. Lett. 90, 155901 (2003).

${ }^{18}$ R. R. Robinson and M. E. Law, Tech. Dig. - Int. Electron Devices Meet., 883 (2002).

${ }^{19}$ A. Dusch, J. Marcon, K. Masmoudi, K. Ketata, F. Olivie, M. Benzohra, and M. Ketata, Nucl. Instrum. Methods Phys. Res. B 186, 360 (2002). 